\title{
ARBORIZAÇÃO NO CENTRO HISTÓRICO DE CAMPOS DOS GOYTACAZES - RJ
}

Ronaldo de Sousa Araújo ${ }^{1 *}$, José Dantas da Silva Neto ${ }^{1}$, Mellyssa Ribeiro Ramos ${ }^{1}$, Sílvio Parodi de Souza ${ }^{1}$, Humberto Carlos Ferreira Rangel ${ }^{1}$ \& Judith Patrícia Early Marques ${ }^{1}$

\section{RESUMO}

ARAÚJO, R.S.; SILVA NETO, J.D.; RAMOS, M.R.; SOUZA, S.P.; RANGEL, H.C.F.; MARQUES, J.P.E. Arborização no Centro Histórico de Campos dos Goytacazes - RJ. Perspectivas Online: Humanas e Sociais Aplicadas, v. 8, n.23, p. 59-70,2018.

Este artigo disponibiliza o resultado de um estudo sobre arborização no centro histórico de Campos dos Goytacazes, área denominada Zona Centro Histórica $(\mathrm{ZCH})$ pelo Plano Diretor e Lei de Uso e Ocupação do Solo. O objetivo do trabalho é verificar a situação da arborização no espaço público do centro histórico, de modo a subsidiar o planejamento e a gestão pública. Para a realização da pesquisa foi realizada revisão bibliográfica, pesquisa documental, levantamento da arborização existente no local, tabulação e análise de dados. A pesquisa resultou no mapeamento da arborização existente na $\mathrm{ZCH}$, que possibilitou a elaboração de uma caracterização e diagnóstico do local. Com a pesquisa, verificou-se que a maior concentração de arborização no centro histórico localiza-se ao longo da avenida beira rio e na região da Praça São Salvador. Pôde-se verificar também que são muitas as áreas sem nenhuma arborização, o que interfere na paisagem urbana e no microclima do local.

Palavras-chave: Arborização; Centro Histórico; Planejamento Urbano. 


\begin{abstract}
This article provides the result of a study on arborization in the historical center of Campos dos Goytacazes, area called Historic Center Zone $(\mathrm{ZCH})$ by the City Plan and Land Use and Land Use Law. The objective of this work is to verify the situation of arborization in the public space of the historic center, in order to subsidize planning and public management. For the accomplishment of the research it was carried out bibliographical review, documentary research, survey of the existing

analysis. The research resulted in the mapping of the existing arborization in the $\mathrm{ZCH}$, which enabled the elaboration of a characterization and diagnosis of the site. With the research, it was verified that the greatest concentration of arborization in the historical center is located along the waterfront avenue and in the region of the San Salvador Square. It could also be verified that many areas are without any afforestation, which interferes in the urban landscape and the microclimate of the place.
\end{abstract} afforestation in the place, tabulation and data

Keywords: Arborization; Historic center; Urban Planning.

\footnotetext{
${ }^{1}$ Institutos Superiores de Ensino do CENSA - ISECENSA. Laboratório de Estudos Urbanos e Ambientais LEUA. Curso de Arquitetura e Urbanismo. Rua Salvador Correa, 139, Centro, Campos dos Goytacazes, RJ, CEP:28035-310, Brasil.

${ }^{2}$ Alunos voluntários PROVIC - Institutos Superiores de Ensino do CENSA - ISECENSA. Rua Salvador Correa, 139, Centro, Campos dos Goytacazes, RJ,CEP: 28035-310, Brasil.

(*) e-mail: r.saraujo@hotmail.com

Data de recebimento: 23/07/2018. Aceito para publicação: 21/12/2018
} 


\section{INTRODUÇÃO}

Áreas urbanizadas são ambientes construídos em ambientes naturais. Segundo Fernandez (1989) urbanização é o processo em que se transforma solo rústico em solo urbano, que são construídas determinadas estruturas (ruas, moradias e edifícios de uso coletivo) e como também a colocação de redes de serviços (água, luz, gás). Este artigo aborda o tema da arborização, enfocando o centro histórico da cidade de Campos dos Goytacazes. Centros históricos das cidades são áreas onde os processos de ocupação são intensos e, muitas vezes, o ambiente natural é extremamente prejudicado.

Em um trabalho de revisão bibliográfica recente Miranda \& Araújo (2014) observaram os debates de cientistas sobre o denominado aquecimento global, em que muitos afirmam que o planeta está em processo de aquecimento, mas também há os que são contrários a esta ideia. $\mathrm{O}$ relatório publicado pelo Painel Intergovenamental sobre Mudanças Climáticas (IPCC, 2013) defende que as ações humanas influenciam fortemente nas mudanças climáticas do planeta, outros cientistas, como o brasileiro Molion (2010), pensam que o homem não consegue interferir no clima global. No entanto, a nível local, ou seja, no microclima, a influência do homem é facilmente percebida.

Gehl (2015) destaca a importância de se buscar uma cidade viva, segura, sustentável e saudável, e o espaço público de qualidade tem uma importância fundamental. Segundo o autor as árvores, o paisagismo e as flores desempenham um papel fundamental no espaço urbano, elas fornecem sombra e são elementos importantes para refrescar e limpar o ar.

A questão da falta de vegetação vai além do tema da arborização. Araújo et al. (2015) observaram que a falta de vegetação afeta a disponibilidade da água em quantidade e qualidade. No espaço da cidade existe a necessidade de árvores plantadas, mas também de áreas verdes em quantidade, como praças e parques urbanos. Campos dos Goytacazes tem sofrido com a degradação de suas áreas de lagoas (ARAÚJO, 2017) e com a perda considerável de áreas verdes. Araújo e Aguirre (2013) demostraram que muitas áreas destinadas a praças na cidade desapareceram ao longo do tempo para dar lugar a diversos tipos de edificações.

O planejamento pode ser dividido em categorias, considerando as diferentes aptidões das áreas da cidade: arborização de passeios em vias públicas; arborização de áreas livres públicas; arborização de áreas internas de lotes e glebas, públicas ou privadas. Assim, considera-se que a arborização pode elevar a permeabilidade do solo e controlar a temperatura e a umidade do ar; interceptar a água da chuva; proporcionar sombra; funcionar como corredor ecológico; agir como barreira contra ventos, ruídos e alta luminosidade; diminuir a poluição do ar; sequestrar e armazenar carbono; bem estar psicológico (PREFEITURA DE SÃO PAULO, 2015).

Alguns critérios devem ser observados para a definição dos locais de plantio como porte das árvores e largura de ruas e passeios. Também é importante considerar a localização das redes subterrâneas e aéreas (água, esgoto, telefonia, energia etc.). O plantio das árvores deve ser feito do lado oposto à rede de energia. Nos casos em que o plantio ocorrer sob as redes de energia, deve-se utilizar árvores de pequeno porte. (GOMES, 2012).

O Plano Diretor de Campos, Lei $n^{0} 7.972$ (CAMPOS DOS GOYTACAZES, 2008a), determina a elaboração do Plano Diretor de Arborização e Áreas Verdes Urbanas para todo o município. No entanto, em dez anos de vigência da lei, este plano de arborização não foi elaborado. A lei não estabelece diretrizes específicas de arborização adequada para o centro histórico. Em processos de revisão do planejamento urbanístico é fundamental que se busque a qualidade da cidade de forma a atender o interesse público (ARAÚJO, 2010), neste caso estudado o aspecto ambiental é preponderante para a humanização do espaço. 
O centro histórico de Campos dos Goytacazes foi denominado como Zona Centro Histórica (ZCH) pelo Plano Diretor, citado acima, e pela Lei de Uso e Ocupação do Solo, Lei $n^{\circ}$ 7.974/2008 (CAMPOS DOS GOYTACAZES, 2008b).

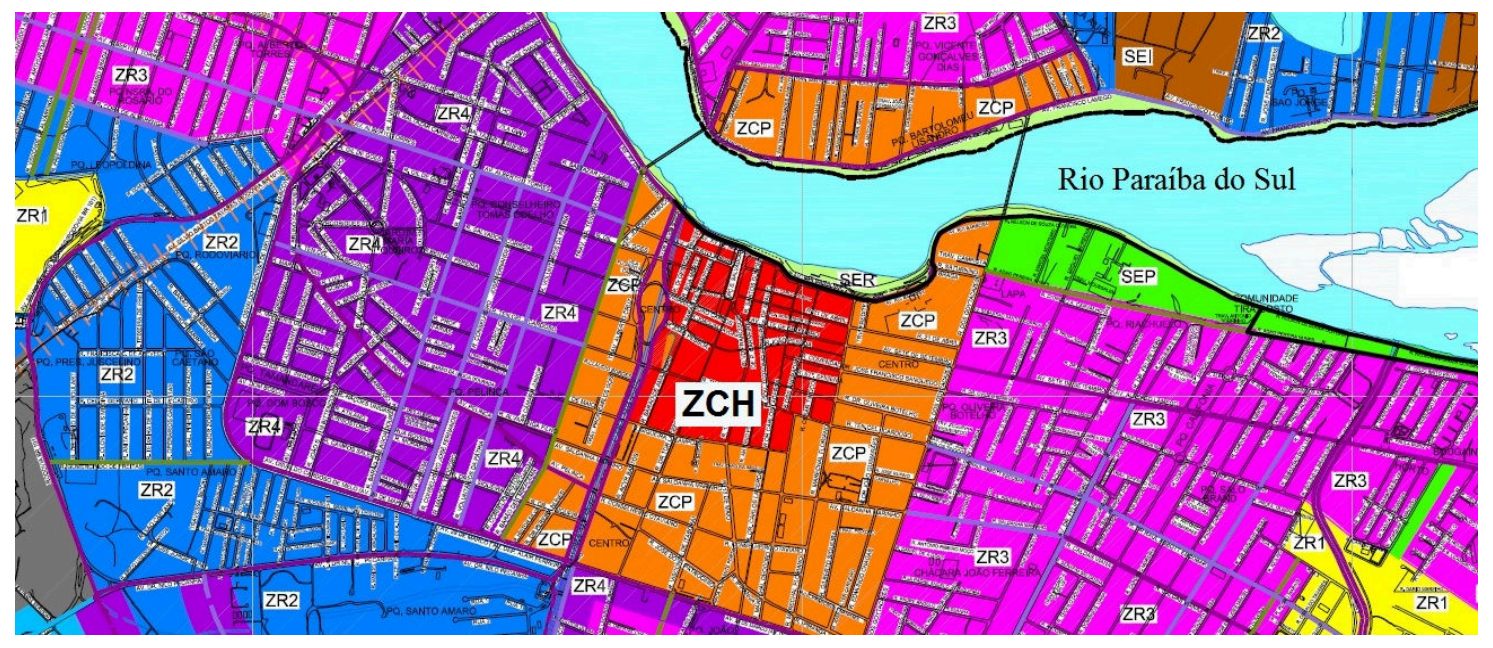

Figura 1. Parte do Mapa de Uso e Ocupação do Solo com a Zona Centro Histórica - ZCH (vermelho) em Campos dos Goytacazes, RJ. Fonte: Anexo III da Lei n 7.974 / 2008, editado pelos autores.

Muitas cidades no mundo possuem Banco de Dados sobre arborização. A cidade de Nova York, por exemplo, realizou um cadastramento da arborização urbana e que está acessível para consulta via internet (NEW YORK, 2018). Entre as informações disponíveis pode-se consultar localização, espécie e características físicas. Em Goiânia, o Plano Diretor de Arborização (PDAU) cadastrou 382 espécies de árvores diferentes nas vias públicas (calçadas, ilhas, praças), em que foi verificado que a espécie predominante é a Monguba com 19\%, e em segundo lugar a Sibipiruna com $17 \%$ de incidência (AMMA, 2018).

Em Barcelona o Plano do Verde e da Biodiversidade buscou uma sintonia com a Estratégia da União Europeia para a biodiversidade até 2020, onde prevalece o pensamento de que os ecossitemas naturais pertencem não somente à cidade, mas são bens coletivos (AJUNTAMENT DE BARCELONA, 2013). O Plano Diretor de Arborização de Barcelona 2017-2037 considera a arborização uma infraestrutura verde, e destaca a importância de aumentar o número de espécies da arborização pública (AJUNTAMENT DE BARCELONA, 2017).

Este trabalho tem como objetivo verificar a situação da arborização no espaço público da Zona Centro Histórica $(\mathrm{ZCH})$ da cidade de Campos dos Goytacazes, estado do Rio de Janeiro, de modo a subsidiar o planejamento e a gestão pública. Os dados levantados nesta pesquisa poderão fazer parte de um amplo Banco de Dados da arborização urbana na ZCH e da cidade. A motivação para a realização deste trabalho partiu da aspiração em contribuir com uma possível requalificação deste espaço, de modo a torná-lo mais humanizado e sustentável. É um trabalho que faz parte do Programa Voluntários de Iniciação Científica - PROVIC dos Institutos Superiores de Ensino do Censa ISECENSA, cujo Projeto de Pesquisa teve como título "Diagnóstico do Centro Histórico de Campos dos Goytacazes: Aspectos Urbanísticos e Ambientais".

\section{METODOLOGIA}

Os processos metodológicos adotados nesta pesquisa foram: revisão bibliográfica; pequisa documental (mapas, leis e normas); levantamento in loco da arborização existente (árvores, palmeiras e arbustos), em que foram realizadas várias visitas técnicas; registro fotográfico de toda a arborização no espaço público; elaboração de mapa com localização da arborização existente; tabulação e análise de dados considerando aspectos quantitativos e qualitativos. Em relação aos aspectos quantitativos 
foram feitas contagens da arborização em toda a área de estudo. A identificação das espécies foi por meio de comparação com publicações especializadas. Sobre os aspectos qualitativos, verificou-se in loco problemas relacionados a plantio e/ou atividades antrópicas.

Além das árvores, as palmeiras e os arbustos também são utilizadas na arborização das cidades (CEMIG, 2011). Desta forma, o levantamento de campo realizado nesta pesquisa visou mapear árvores, palmeiras e arbustos no espaço público da Zona Centro Histórica (ZCH) de Campos dos Goytacazes. Para o levantamento de coordenadas foi utilizado o receptor GPS/GNSS Trimble 5700 e para o levantamento cadastral das palmeiras-imperiais (Roystonea oleracea) foi utilizada Estação Total Eletrônica TKS 202.

\section{RESULTADOS E DISCUSSÃO}

O levantamento in loco possibilitou a realização de um mapa de localização de toda a arborização urbana na Zona Centro Histórica (Figura 2), dividida em duas situações: plantio no solo e plantio em vaso. Desta arborização cadastrada, 175 unidades (entre árvores, palmeiras e arbustos) estão plantadas no solo e 24 estão plantadas em vaso, somando um total de 199 unidades.

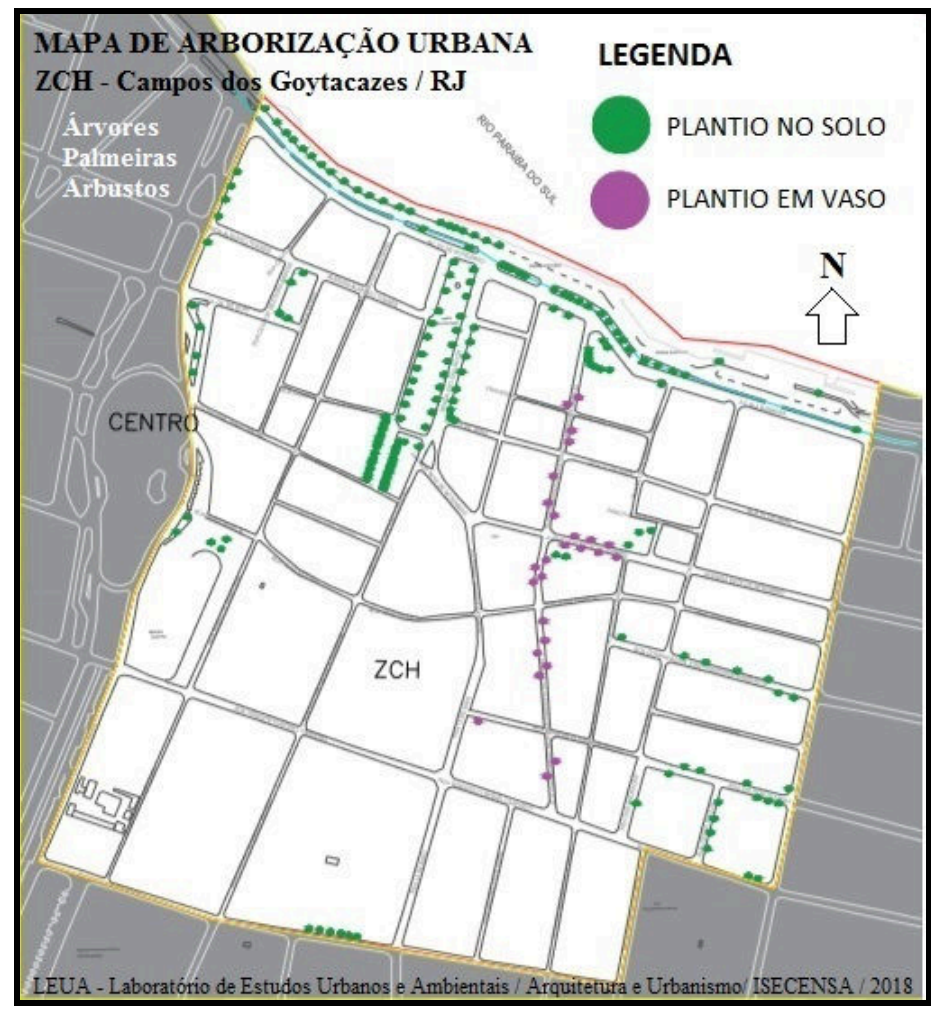

Figura 2. Mapa com resultado do levantamento da arborização na Zona Centro Histórica de Campos dos Goytacazes, RJ.

A análise dos dados possibilitou a identificação das principais espécies existentes na Zona Centro Histórica de Campos. Das espécies identificadas, verificou-se que a espécie predominante é a Palmeira Veitchia com 21\% de incidência, em segundo lugar está a Palmeira-Imperial (Roystonea oleracea) com $18 \%$ de incidência. A Palmeira Veitchia foi plantada em vaso e colocada em locais onde houve obra de requalificação urbana. A Palmeira Imperial foi plantada no solo, praça São Salvador, local que já passou por algumas mudanças em sua estrutura urbana e paisagística (Quadro $1)$.

Quadro 1. Arborização Urbana na Zona Centro Histórica de Campos dos Goytacazes, RJ 


\begin{tabular}{|c|c|c|c|c|c|c|}
\hline $\mathbf{N}^{\circ}$ & NOME POPULAR & NOME CIENTIFICO & SIGLA & PLANTIO & TOTAL & $\%$ \\
\hline 1 & PALMEIRA VEITCHIA & Veitchia merrillii & VEME & VASO & 35 & 21 \\
\hline 2 & PALMEIRA-IMPERIAL & Roystonea oleracea & ROOL & SOLO & 30 & 18 \\
\hline 3 & OITI & Licania tomentosa & LITO & SOLO & 18 & 11 \\
\hline 4 & FICUS & Ficus benjamina & FIBE & SOLO & 15 & 9 \\
\hline 5 & IPÊ AMARELO & Tabebuia chrysotricha & TACH & SOLO & 13 & 8 \\
\hline 6 & FLAMBOYANT & Delonix regia & DERE & SOLO & 9 & 5 \\
\hline 7 & MURTA & Murraya paniculata & MUPA & SOLO & 9 & 5 \\
\hline 8 & SIBIPIRUNA & Caesalpinia peltophoroides & CAPE & SOLO & 6 & 4 \\
\hline 9 & PATA-DE-VACA & Bauhinia variegata & BAVA & SOLO & 5 & 3 \\
\hline 10 & MANGUEIRA & Mangifera indica & MAIN & SOLO & 4 & 2 \\
\hline 11 & ARECA BAMBU & Dypsis lutescens & DYLU & SOLO & 3 & 2 \\
\hline 12 & GOIABEIRA & Psidium tomentosa & PSGU & SOLO & 3 & 2 \\
\hline 13 & PALMEIRA FÊNIX & Phoenix roebelenii & PAPH & SOLO & 3 & 2 \\
\hline 14 & PAU FERRO & Caesalpinia leiostachya & CALE & SOLO & 2 & 1 \\
\hline 15 & PAU FORMIGA & Triplaris americana & TRAM & SOLO & 2 & 1 \\
\hline 16 & AMENDOEIRA & Terminalia catappa & TECA & SOLO & 2 & 1 \\
\hline 17 & PÂNDALO & Pandanus utilis & PAUT & SOLO & 2 & 1 \\
\hline 18 & IPÊ ROSA & Tabebuia avellanedae & TAAV & SOLO & 1 & 1 \\
\hline 19 & GUANDO & Cajanus cajan & CAJA & SOLO & 1 & 1 \\
\hline 20 & YUCA ELEFANTE & Yucca elephantipes & YUEL & VASO & 1 & 1 \\
\hline 21 & AROEIRA MANSA & Schinus terebinthifolius & SCNO & SOLO & 1 & 1 \\
\hline 22 & AMORA & Morus nigra & MONI & SOLO & 1 & 1 \\
\hline 23 & PINGO-DE-OURO & Duranta repens & DURE & SOLO & 1 & 1 \\
\hline 24 & DRACENA VERMELHA & Cordyline terminalis & COTE & SOLO & 1 & 1 \\
\hline & & & 168 & 100 \\
\hline
\end{tabular}

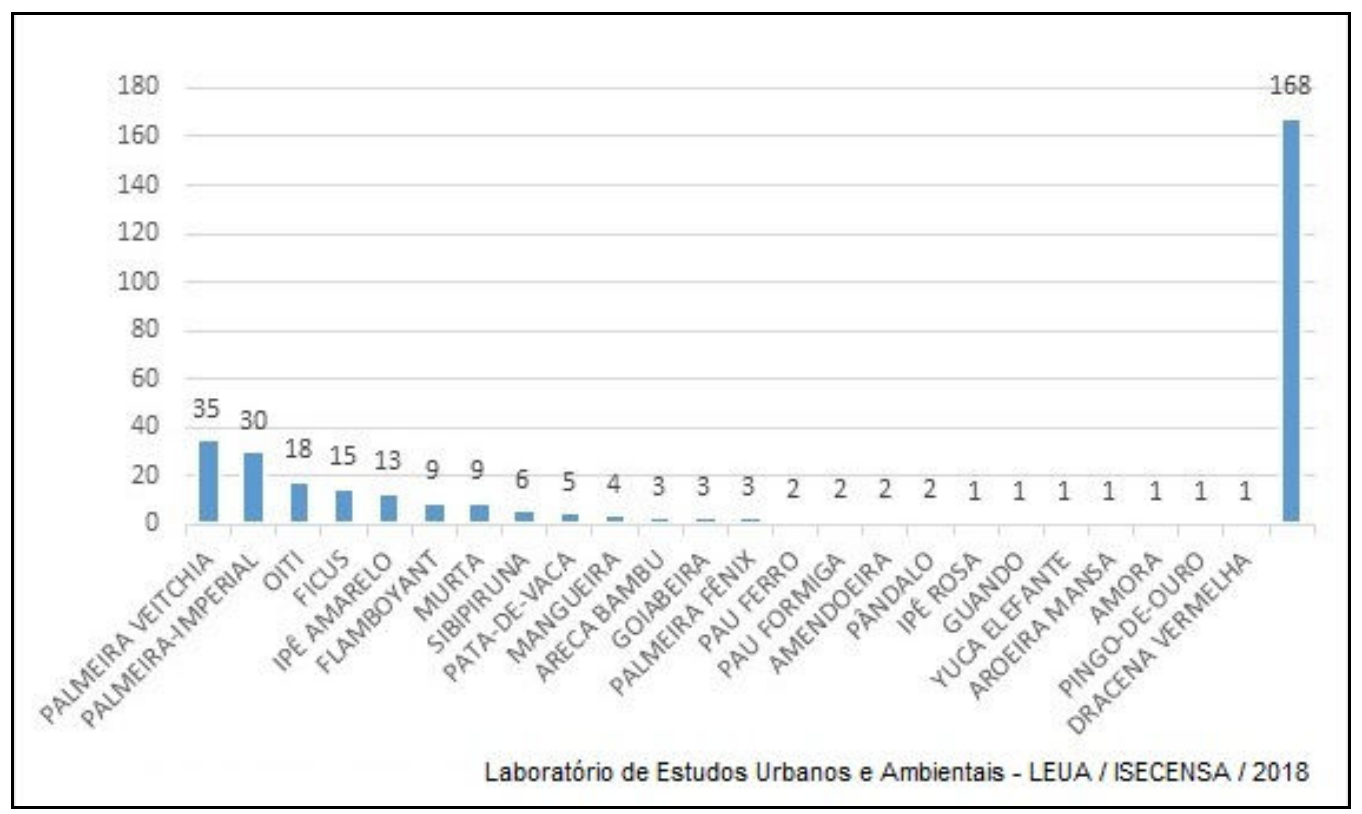

Figura 3. Gráfico com incidência das espécies vegetais na Zona Centro Histórica de Campos dos Goytacazes, RJ.

Nas figuras a seguir, pode-se observar exemplos das principais espécies que incidem na Zona Centro Histórica. As palmeiras são as plantas em maior quantidade no local. Oiti e ficus são árvores frondosas, que proporcionam bastante sombra, mas precisam de espaço. Observa-se um flamboyant, árvore ornamental de grande porte, plantada na orla do Rio Paraíba do Sul (Figura 5c). 


\section{PERSPECTIVAS online}
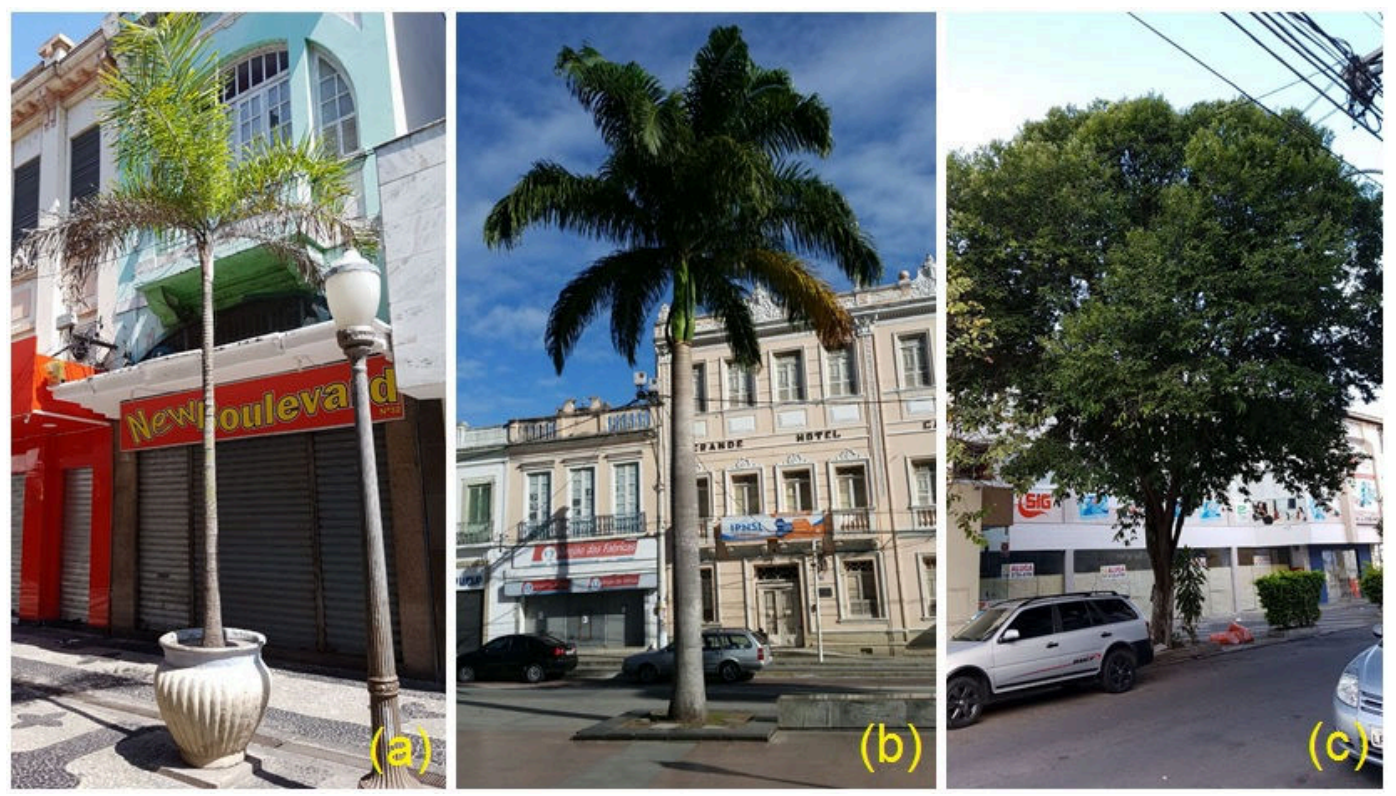

Figura 4. Palmeira Vetchia (a), Palmeira Imperial (b) e Oiti (c) na Zona Centro Histórica em Campos dos Goytacazes, RJ.
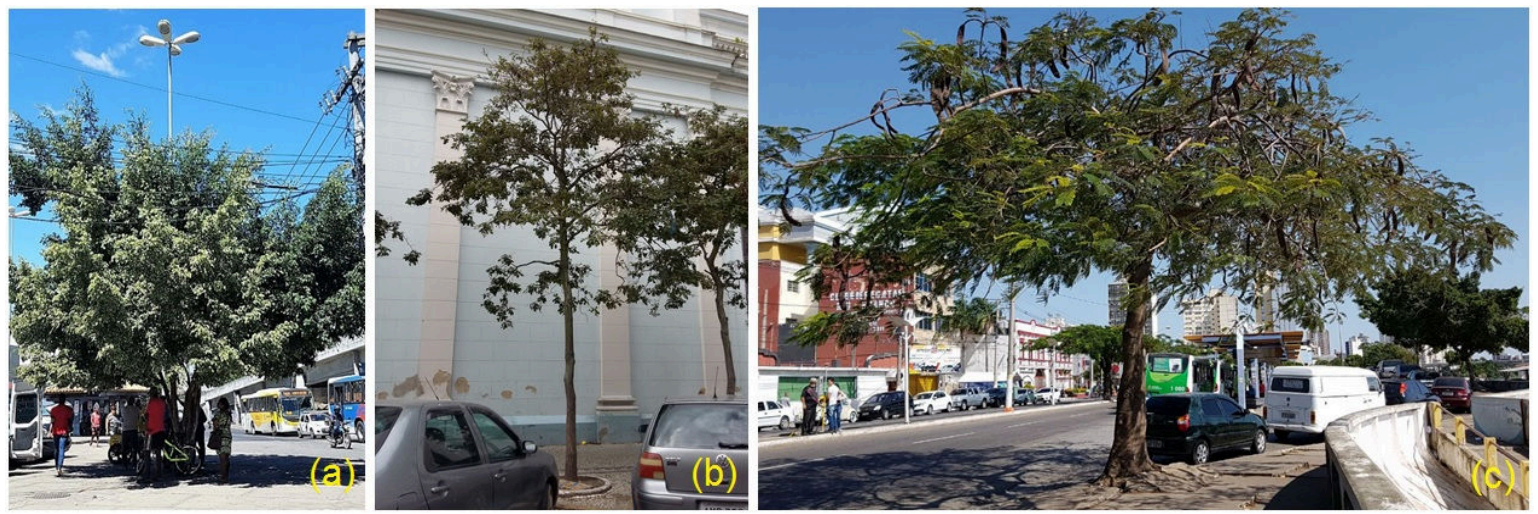

Figuras 5. Ficus (a), Ipê Amarelo (b) e Flamboyant (c) na Zona Centro Histórica de Campos dos Goytacazes, RJ.

Podem compor o Banco de Dados da arborização, além de informações como espécie e porte, coordenadas geográficas ou UTM resultantes de levantamento. Nesta pesquisa foi realizado o levantamento das coordenadas da vegetação na praça São Salvador. Foram levantadas 24 palmeiras imperiais que estão dispostas na praça em duas colunas. Verifou-se nos dados levantados, pequenas diferenças de alinhamento das palmeiras. O levantamento por coordenadas pode ser ampliado para toda a ZCH e para toda a cidade, fazendo parte de um amplo banco de dados. 


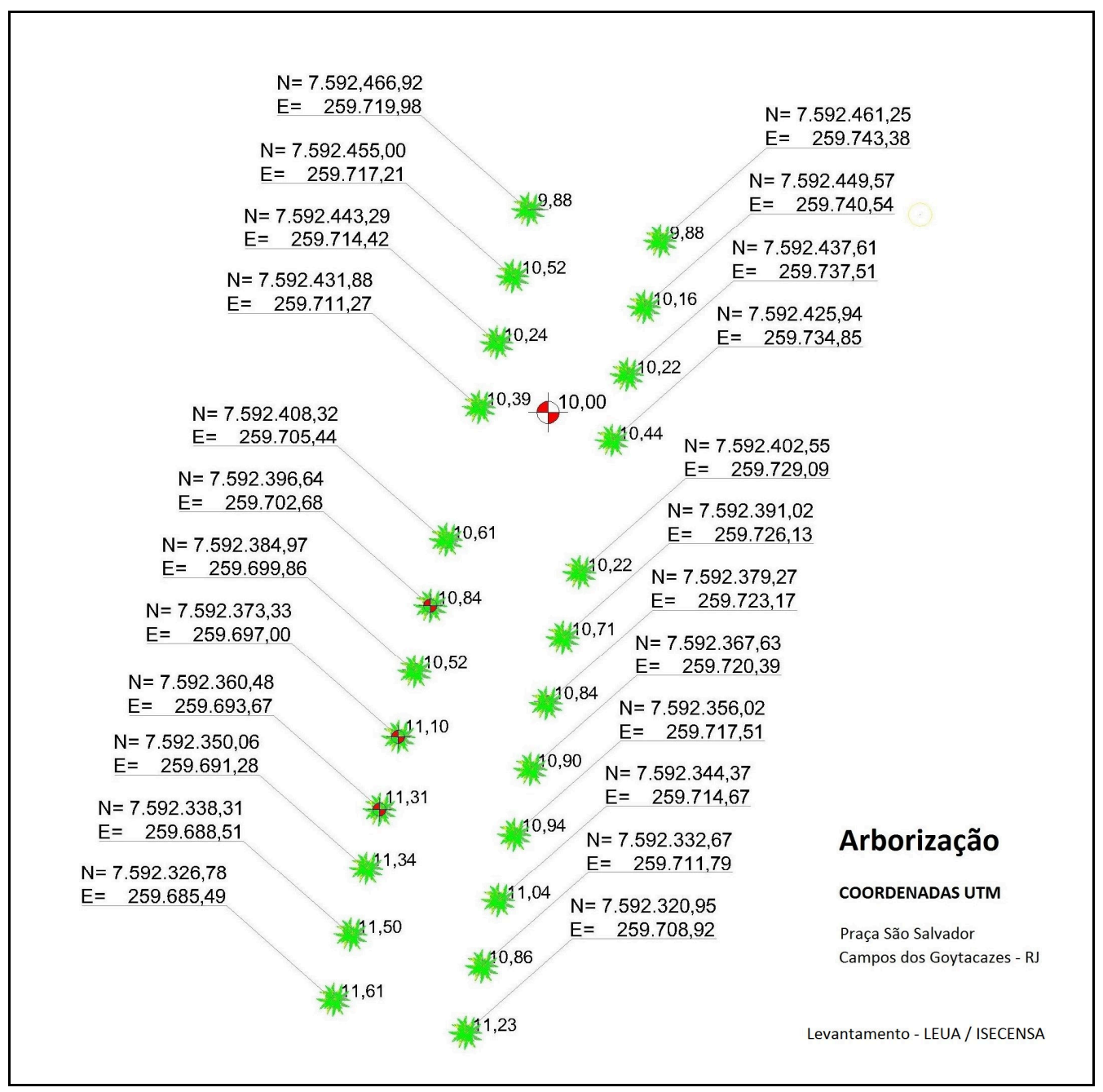

Figura 6. Mapa de localização de palmeiras imperiais na praça São Salvador em Campos dos Goytacazes, RJ.

Segundo Sousa (1935), em Campos dos Goytacazes o primeiro local a receber o benefício da arborização foi a Beira Rio em 1857, ocasião em que foram plantadas 50 mudas de nogueira da Índia.

$\mathrm{Na}$ análise do mapa de localização da arborização (Figura 2), verifica-se uma maior concentração de vegetação na região da praça São Salvador e ao longo da orla do Rio Paraíba do Sul, que são as áreas mais amplas da ZCH. Verifica-se que nas ruas mais estreitas a incidência de arborização é menor, especialmente por se tratar de uma zona com predominância de comércio e serviço. Algumas ruas são totalmente desprovidas de arborização.

A diminuição da arborização em centros urbanos é uma realidade, isto ocorre, muitas vezes, pela grande incidência de estabelecimento comerciais, visto que a vegetação é considerada incompatível com a visibilidade dos letreiros das empresas. Na região estudada observou-se, através dos registros fotográficos, que ao longo do tempo houve uma diminuição considerável de arborização (Figuras 7, 8 e 9).

Em décadas passadas, a arborização também se dava nos locais anteriormente citados, mas também era significativa em outros locais da cidade, como na Rua Alberto Torres (Figura 7a). Atualmente esta rua encontra-se com pouquíssima arborização na ZCH (Figura 7b). Considerando as reflexões de Gehl (2015), em relação a importância da arborização, neste trecho de via a ausência de árvores tende a interferir no microclima e na qualidade urbana na escala humana. Nas Figuras 8 e 9 , verifica-se o desaparecimento de vegetação nas Avenida 15 de Novembro (Beira Rio) e Avenida 7 de 


\section{PERSPECTIVAS online}

Setembro.
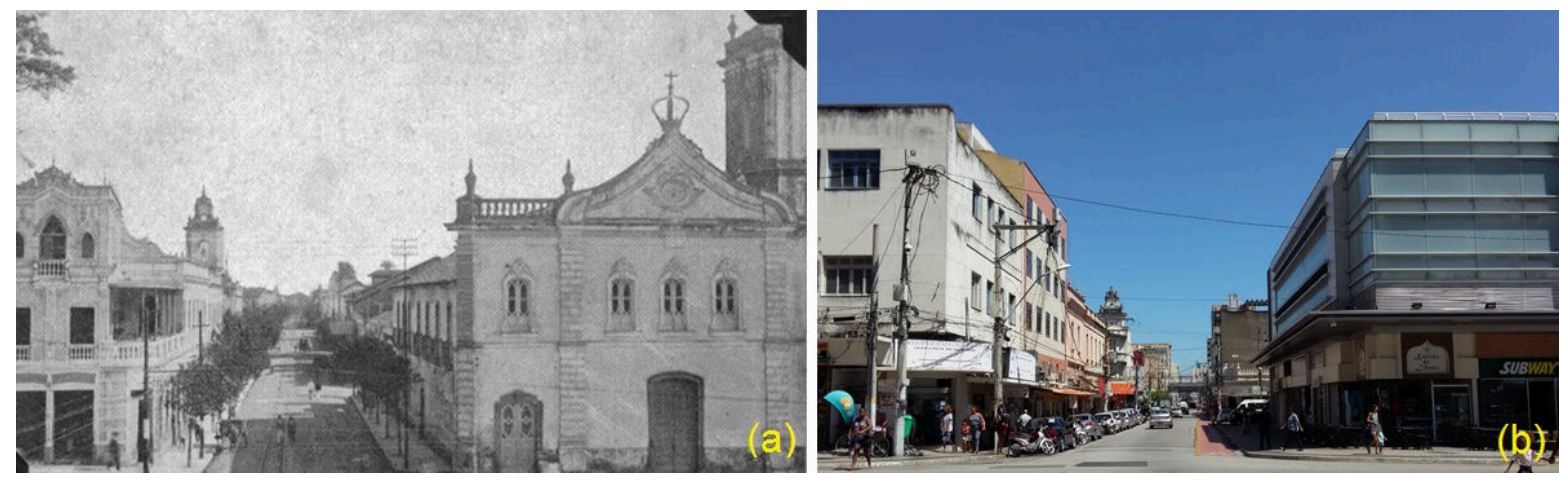

Figura 7. Imagens antigas (a) e atual (b) da Rua Alberto Torres na Zona Centro Histórica em Campos dos Goytacazes, RJ. (Fotos: Ralphbraz e acervo dos autores).
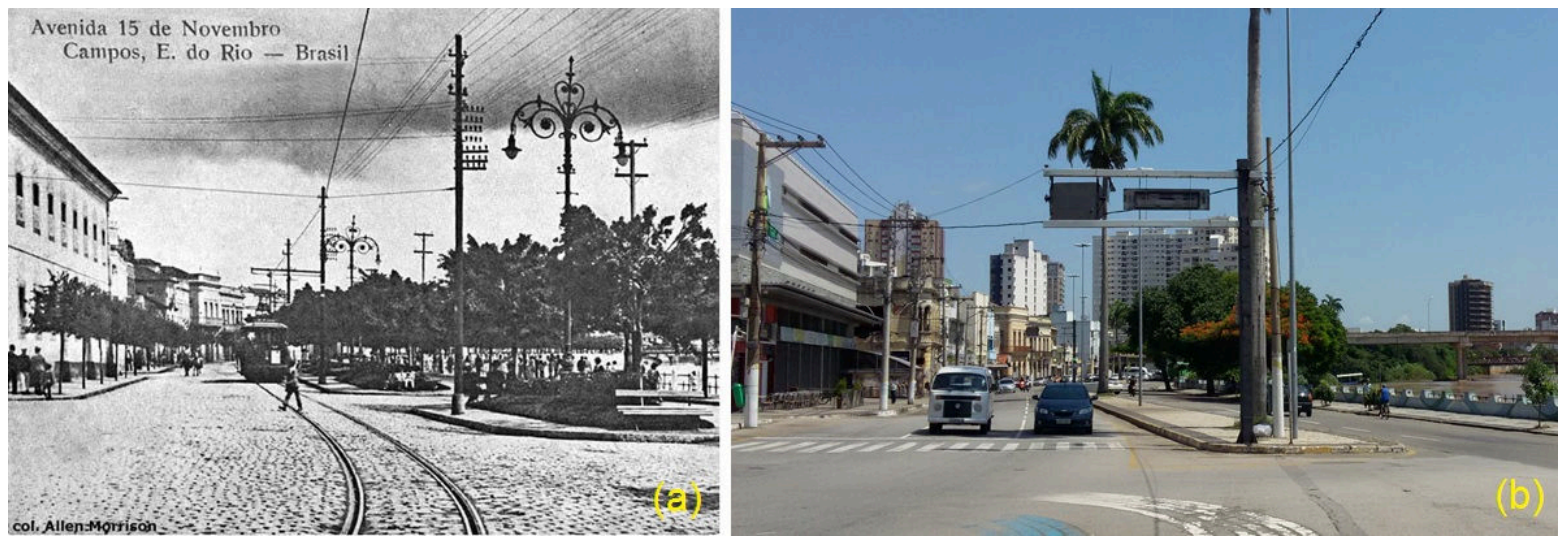

Figura 8. Imagens antigas (a) e atual (b) da Avenida 15 de Novembro (Beira Rio) na Zona Centro Histórica em Campos dos Goytacazes, RJ. (Fotos: col. Allen Morrison e acervo dos autores).
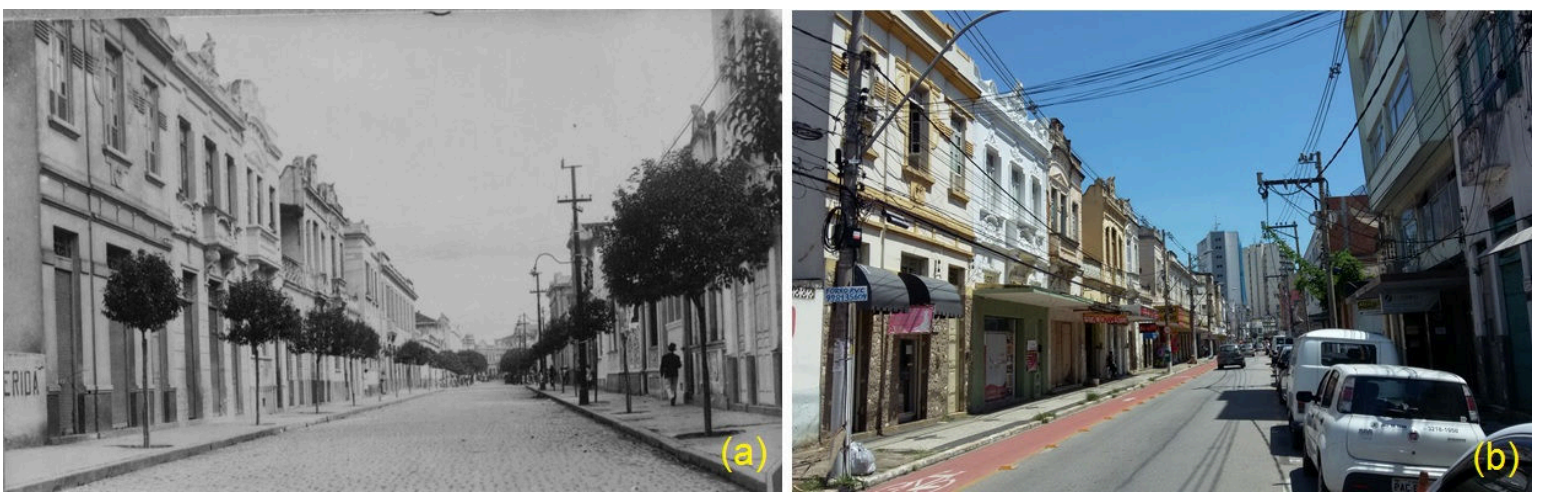

Figura 9. Imagens antigas (a) e atual (b) da Avenida 7 de Setembro na Zona Centro Histórica em Campos dos Goytacazes, RJ. (Fotos: Arquivo Campos Antiga e acervo dos autores).

Nas áreas na ZCH onde existe vegetação plantada em vaso, houveram intervenções urbanas recentes. Locais onde predomina a incidência de palmeiras. O plantio de palmeiras em vaso é uma boa alternativa para locais com pouco espaço, como as calçadas estreitas onde alguns autores não recomendam o plantio (Gomes, 2012). A mesma possibilidade também se aplica para áreas comerciais, onde as palmeiras pouco interferem na visão das fachadas de empresas. 
$\mathrm{Na}$ ZCH ocorrem situações em que as plantas estão envolvidas em algum problema ou inadequação. Verificou-se situações de incompatibilidade da arborização com a infraestrura urbana: falta de integração da arborização e a rede de energia elétrica (Figura 10a); inadequação da pavimentação com as características da planta, raízes danificando o piso (Figura 10b). Também foi verificada a supressão de arborização sem reposição (Figura 10c). A inexistência de arborização, em locais pré-definidos como área de plantio, pode ser por motivos diversos, entre as hipóteses prováveis pode-se citar vandalismo, falta de cuidado, incidência de pragas ou mesmo falta de plantio.
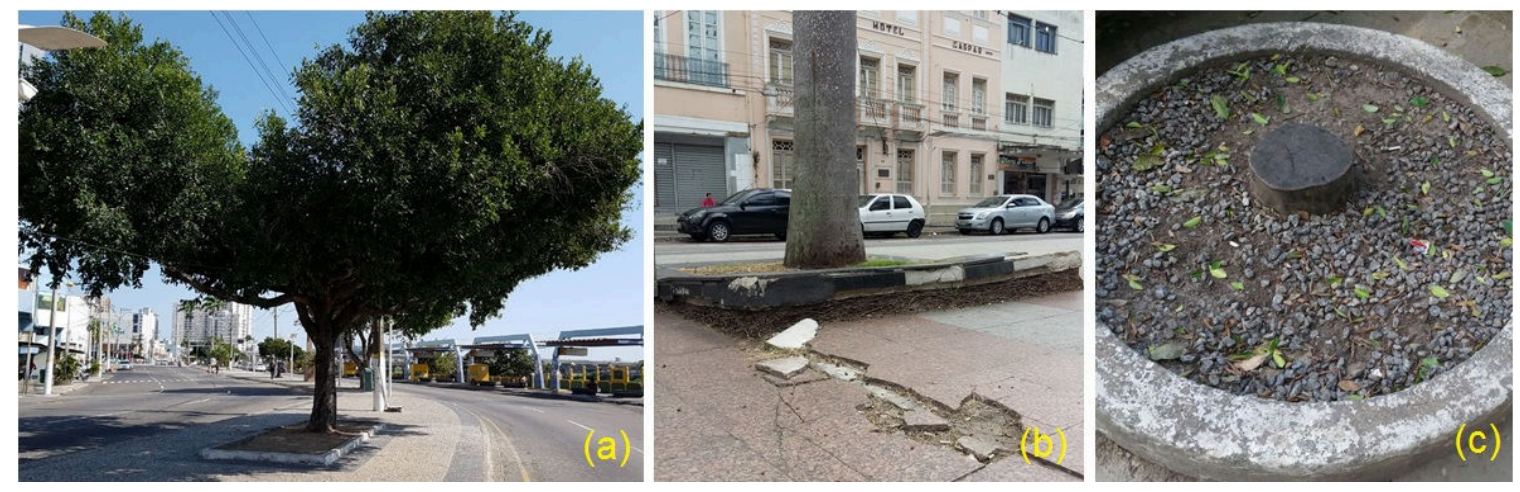

Figura 10. Conflito entre uma planta e a rede de energia elétria (a); incompatibilidade de raízes e pavimentação (b); supressão da arborização (c). Zona Centro Histórica em Campos dos Goytacazes, RJ.

Na Figura 11(a, b e c) pode-se observar a colocação de vasos em duas situações, em calçadão e em calçada. Nas duas situações a localização está adequada, no entanto percebe-se alguns problemas.
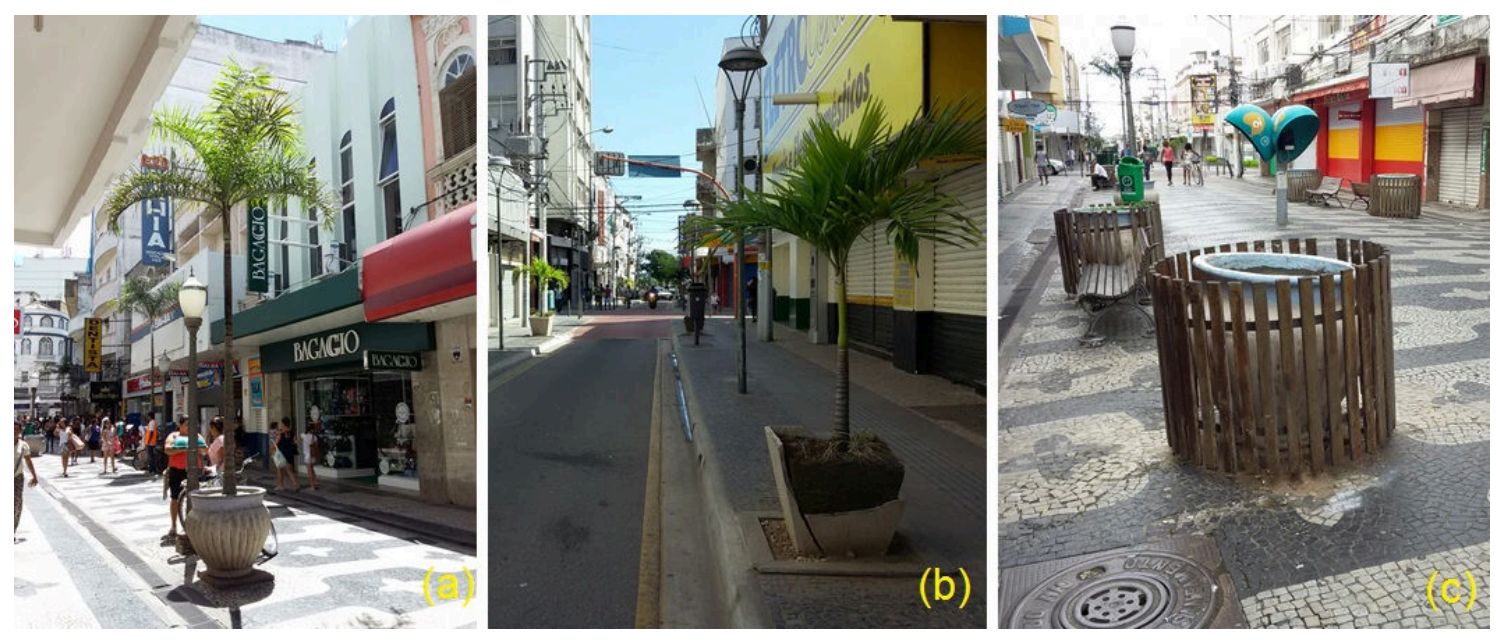

Figura 11. Vasos para arborização na Zona Centro Histórica em Campos dos Goytacazes, $\mathrm{RJ}(\mathrm{a})$; ragilidade dos vasos(b); Ausência de plantas(c).

Campos dos Goytacazes ainda não dispõe de um Plano Diretor de Arborização Urbana e/ou de um mapa digital disponível na internet. Estes documentos são importantes para a preservação ambiental e a qualidade urbana. Analisando os resultados da pesquisa pode-se constatar a carência de arborização na Zona Centro Histórica de Campos, e que houve perda de arborização ao longo do tempo nesta região da cidade.

Em estudo realizado na região da Praça do Liceu, também em Campos dos Goytacazes, Morais et al. (2011) observaram vários problemas, entre os quais: problemas com raízes danificando calçadas; árvores impedindo a mobilidade; muitas podas consideradas drásticas; predominância de 
plantas de espécies exóticas sobre as nativas.

A cidade de Campos dos Goytacazes, está localizada em região de Mata Atlântica / Restinga, assim, na recomposição da arborização, e na ampliação de toda a composição vegetal, é importante valorizar as espécies vegetais deste ecossistema (ver FREIRE et al., 2015). No entanto, as espécies nativas que não há informações do seu comportamento no meio urbano, recomenda-se que sejam realizados plantios experimentais de forma a possibilitar o monitoramento (GOMES, 2012).

\section{CONCLUSÕES}

Verificou-se nesta pesquisa que a arborização na Zona Centro Histórica - ZCH não representa as necessidades da população em relação a um ambiente agradável (sombra, baixas temperaturas), beleza da paisagem e referências culturais. Aspectos fundamentais para a humanização e sustentabilidade urbana.

Em áreas de interesse histórico, existe uma demanda em se planejar uma arborização compatível com as características específicas do local. Na ZCH de Campos dos Goytacazes entende-se que a arborização deve ser planejada de modo a valorizar o interesse histórico das contruções e do espaço urbano, melhorar o microclima do local, atender as demandas da infraestrutura (especialmente redes de energia) e contribuir com a beleza da paisagem urbana. Um planejamento com a utilização de maior variedade de espécies de plantas, especialmente espécies nativas do Brasil e da região de restinga.

Contudo, é importante observar que além da necessidade de arborização em quantidade e qualidade, como demonstrou este estudo na Zona Centro Histórica de Campos, é fundamental que a cidade disponibilize áreas verdes, como praças e parques urbanos, de forma a proporcionar qualidade de vida para a população.

\section{REFERÊNCIAS}

AJUNTAMENT DE BARCELONA. Plan del verde y de la biodiversidad de Barcelona 2020. Barcelona: Abril 2013.

AJUNTAMENT DE BARCELONA. Árboles para vivir. Plan director del arbolado de Barcelona 2017-2037. Barcelona: 2017.

ARAÚJO, R.S. Modificações no planejamento urbanístico: teoria e método de análise. São Paulo: Editora Nobel, 2010.

ARAÚJO, R.S. \& AGUIRRE, C.A.F. Espaços públicos: áreas verdes em Campos dos Goytacazes e São João da Barra - RJ. Perspectivas online: humanas \& sociais aplicadas, Campos dos Goytacazes, 8 (3), 56-77, 2013.

ARAÚJO, R.S.; ALVES. M.G.; MELO, M.T.C.; CHRISPIM, Z.M.P.; MENDES, M.P.; SILVA JÚNIOR, G.C. Water resource management: A comparative evaluation of Brazil, Rio de Janeiro, the European Union, and Portugal. Science of the Total Environment, v.511, pp. 815-828, 2015.

ARAÚJO, R.S. Resgatando a lagoa para a cidade. Boletim de Pesquisa e Desenvolvimento do ISECENSA. Campos dos Goytacazes, v.1, n.2, 2017, p.28-31.

AMMA - AGÊNCIA MUNICIPAL DE MEIO AMBIENTE DE GOIÂNIA. Unidades de Conservação - $\quad$ Arborização Urbana. Disponível em: http://www.goiania.go.gov.br/shtml/amma/arborizacao.shtml. Acesso em: 13/03/2018. 
CAMPOS DOS GOYTACAZES. Lei $n^{\circ} 7.972$, de 31 de março de 2008. Institui o Plano Diretor de Campos dos Goytacazes. Campos dos Goytacazes: Câmara Municipal, 2008a.

CAMPOS DOS GOYTACAZES. Lei $n^{\circ}$ 7.974, de 31 de março de 2008. Institui a Lei de Uso e Ocupação do Solo Urbano do Município de Campos dos Goytacazes. Campos dos Goytacazes: Câmara Municipal, 2008b.

CEMIG - COMPANHIA ENERGÉTICA DE MINAS GERAIS. Manual de Arborização. Belo Horizonte: CEMIG / Fundação Biodiversitas, 2011.

FERNANDEZ, A.C. Instituciones de Derecho Urbanistico. 4a Edición. Madrid: Editorial Montecorvo, 1989.

FREIRE, M.G.M.; MUSSI-DIAS, V.; SIQUEIRA, G.M.B.; NASCIMENTO, D.F. O tempo e a restinga. Campos dos Goytacazes: M.G.M. Freire, 2015.

GEHL, J. Cidades Para Pessoas. 3 ed. São Paulo: Editora Perspectiva, 2015.

GOMES, P.B. (Org.). Manual para elaboração do Plano Municipal de Arborização Urbana. Comitê de Trabalho Interinstitucional para Análise dos Planos Municipais de Arborização Urbana no Estado do Paraná (APEF, COPEL, CREA-PR, EMBRAPA-FLORESTAS, IAP, EMATER, MP-PR, SANEPAR). Paraná: 2012.

IPCC - INTERGOVERNMENTAL PANEL ON CLIMATE CHANGE. Climate Change 2013: The Physical Science Basis. New York: Cambridge University Press, 2013.

MIRANDA, L.A.; ARAÚJO, R.S. Mudanças Climáticas: Análise de dois pontos de vista. Persp. Online: hum. \& sociais, aplicadas, Campos dos Goytacazes, 9 (4), 47-55, 2014.

MOLION, L.C.B. Desmistificando o Aquecimento Global. Instituto de Ciências Atmosféricas. Universidade Federal de Alagoas. Disponível https:/www.institutodeengenharia.org.br/site/2010/01/22/desmistificando-o-aquecimento-global/.

Acesso em: 03/03/2018.

MORAIS, V.; SOUZA, C.L.M.; LANDGRAF, P.R.C. Arborização Urbana: uma situação em Campos dos Goytacazes. Perspectivas online: ciências biológicas e da saúde, Campos dos Goytacazes, v.1, $\mathrm{n}^{\circ}$ 1, 2011, pp. 60-69. Disponível em: seer:perspectivasonline.com.br.

NEW YORK. New York City Street Tree Map. Disponível em: https://tree-map.nycgovparks.org. Acesso em: 09/03/2018.

PREFEITURA DE SÃO PAULO. Secretaria Municipal do Verde e Meio Ambiente. Manual técnico de arborização urbana. São Paulo: 2015. Disponível em: http://www.prefeitura.sp.gov.br/cidade/secretarias/meio_ambiente.

SOUSA, H. Cyclo Aureo: História do $1^{\circ}$ centenário da cidade de Campos 1835-1935. Campos dos Goytacazes, RJ: Essencia, 2014 (Memórias Fluminenses; v.1). Reedição da obra original de 1935. 